\title{
COMPARATIVE EVALUATION OF MECHANICAL PROPERTIES OF THREE RESIN COMPOSITE MATERIALS WITH DIFFERENT FILLER PARTICLE SIZES
}

\author{
Amal M. El Shahawi* and Mai M. Elbatanony*
}

\begin{abstract}
Aim: The aim of this study was to evaluate and compare the mechanical properties of three resin composites core materials with different filler particle sizes.

Materials and methods: nanofilled (Filtek Z350 XT , 3M, ESPE USA), microhybrid (Te Econom, Ivoclar, Vivadent, India) and nanohybrid (Nexcomp, Meta biomed, korea) resin composites were used during this study. Mechanical properties regarding the compressive strength, diametral tensile strength and surface hardness were tested. Data were statistically analyzed using one-way Analysis of Variance and Tukey HSD test.
\end{abstract}

Results: The nanofilled type revealed the highest significant compressive and diametral tensile strength values while the nanohybrid type showed the least significant hardness values.

Conclusions: the tested nanofilled resin composite type is more appropriate for use as core material compared to the other tested types.

KEYWORDS: Core composite, nanofilled composite, microhybrid composite, nanohybrid composite, compressive strength, tensile strength, hardness.

\section{INTRODUCTION}

Recently, more than half of the posterior restorations depend on resin composites. Unfortunately, the need of these restorations in attention to mechanical properties leave a spacious room for more improvements, especially with attention to their difference in thermal expansion, polymerization shrinkage, polymerization stresses in addition to wear resistance, marginal leakage, and toxicity ${ }^{(1)}$.
Strength is an important value for choice of a core material; it should allow sufficient tensile and compressive strength (CS) to resist multidirectional masticatory forces. This will provide better resistance and more uniform stress distribution, with less tensile or compressive failure. ${ }^{(2-5)}$.

Dental resin composites have been classified mainly according to their average size of the inorganic fillers ${ }^{(6 .)}$. Nanocomposites, have been introduced in the market for their claimed good

\footnotetext{
* Researcher at Restorative and Dental Materials Department, National Research Centre, Cairo.
} 
mechanical properties, superior polishabilty, high wear resistance, excellent optical features and low polymerization shrinkage. The nanohybrid types encompass mainly milled glass fillers and isolated nanoparticles. The nanofilled types, on the other hand contain discrete nano filler particles and agglomerated particles "nanoclusters", to provide reinforcement mechanism improving their strength compared to other composite types. Other classification methods of composite resin were proposed, due to differences found in the mechanical properties within each group due to differences found in their composition. The mechanical behavior of their organic matrix was ignored despite of the proved direct influence on their mechanical performance. Therefore; this study was conducted to evaluate and compare the compressive strength, diametral tensile strength and hardness of three different composite core materials to certify differences in their properties.

\section{MATERIALS AND METHODS}

Three types of commercially available resin composite core materials were used in this study and are represented in table (1)

A total of 45 specimens were prepared for this study. The specimens were divided into three main groups according to resin composite filler type $(\mathrm{n}=$ 15); first group: the nanofilled resin composite, second group: the microhybrid resin composite and the third group: nanohybrid resin composite. Each group were then subdivided into 3 subgroups $(n=5)$ for compressive strength, diametral tensile and surface hardness testing.

\section{Compressive strength testing (CS)}

Five cylindrical specimens $(6 \times 4 \mathrm{~mm})$ of each composite type were prepared according to ADA specification no. $27^{(7)}$ using split Teflon molds. Each specimen was incrementally filled into the mold between two glass slabs covered with Mylar strip and photo-cured (Triad 2000, Dentsply, York, PA) for $40 \mathrm{sec}$. Excess material was removed using soflex discs. The specimens were then incubated at $37^{\circ} \mathrm{C}$ for $24 \mathrm{~h}$ before testing.

Compressive strength testing was done using Universal testing machine (Shimadzu 5KN Autograph AG-Xplus, Japan) with load cell 50N and cross head speed $0.5 \mathrm{~cm} / \mathrm{min}^{(8)}$. The compressive strength (MPa) was automatically calculated using a software (TrapeziumX, Nexus 4000TM, Innovatest,model no.4503, Netherland) supplied by the machine.

TABLE (1)

\begin{tabular}{|l|l|l|l|}
\hline Material & Manufacturer & Composition & Type \\
\hline Filtek Z 350 XT & 3M,ESPE, USA & $\begin{array}{l}\text { Matrix: Bis-GMA, UDMA, Bis-EMA,TEGDMA, } \\
\text { PEGDMA. } \\
\text { Fillers: nanosilica, nano zirconia, nanoclusters (0.6-10 } \mu \mathrm{m}) \\
(78.5 \mathrm{wt} \%)\end{array}$ & Nanofilled \\
\hline Te Econom & $\begin{array}{l}\text { Ivoclar, } \\
\text { Vivadent, India }\end{array}$ & $\begin{array}{l}\text { Matrix: Dimethacrylate, TEGDMA } \\
\text { Fillers: barium glass, ytterbium trifluoride, silicon } \\
\text { dioxide(76\% wt) }\end{array}$ & Microhybrid \\
\hline Nexcomp & Meta, & $\begin{array}{l}\text { Matrix: Bis-GMA, Bis-EMA,UDMA,TEGDMA } \\
\text { Fillers: } 0.04-0.7 \mu \text { m barium aluminum boro silicate }(75 \% \\
\text { wt) }\end{array}$ & Nanohybrid \\
\hline
\end{tabular}




\section{Diametral tensile strength testing (DTS)}

Five disc specimens $(6 \times 3 \mathrm{~mm})$ were prepared using split Teflon molds according to ADA specification no. $27^{(7)}$. Specimens were prepared as previously mentioned in compressive strength testing. Diametral tensile strength testing was done using universal testing machine (Shimadzu $5 \mathrm{KN}$ Autograph AG-Xplus, Japan) under compressive load at a cross head speed of $0.5 \mathrm{~cm} / \mathrm{min}$ and load cell $50 \mathrm{~N}$. Load to failure was recorded and the DTS (MPa) was calculated according to the following equation:

$$
\mathrm{DTS}=2 \mathrm{P} / \pi \mathrm{DL}
$$

where $\mathrm{P}$ is the load at failure $(\mathrm{N}), \mathrm{D}$ and $\mathrm{L}$ are diameter and height $(\mathrm{mm})$ of specimens, respectively ${ }^{(8)}$.

\section{Surface hardness testing}

Five disc specimens $(5 \times 2 \mathrm{~mm})$ were prepared using split Teflon molds ${ }^{(9)}$. Surface hardness was tested using $100 \mathrm{~g}$ force for 15 seconds dwell time usingVickers hardness tester (NEXUS 4000 TM, INNOVATEST, model no.4503, Netherlands). Three indentations were made randomly in each specimen's surface ${ }^{(9)}$.

\section{Statistical analysis}

The results were collected and tabulated. Statistical analysis was performed using IBM, SPSS ${ }^{\circledR}$ Statistics Version 20 for Windows (SPSS Inc., IBM Corporation; USA). One-way Analysis of Variance (ANOVA) and Tukey HSD test were used. The mean and standard deviation values were calculated. The significance level was set at $\mathrm{P} \leq$ 0.05 .

\section{RESULTS}

\section{Compressive strength results}

Results of compressive strength testing are shown in figure (1). The nanofilled resin composite type revealed the highest significant compressive strength value (256.4MPa) compared to the micohybrid (179.3MPa) and the nanohybrid $(143 \mathrm{MPa})(\mathrm{p}<0.05)$. No significant difference was found between the micohybrid and nano hybrid types $(\mathrm{p}=0.27)$.

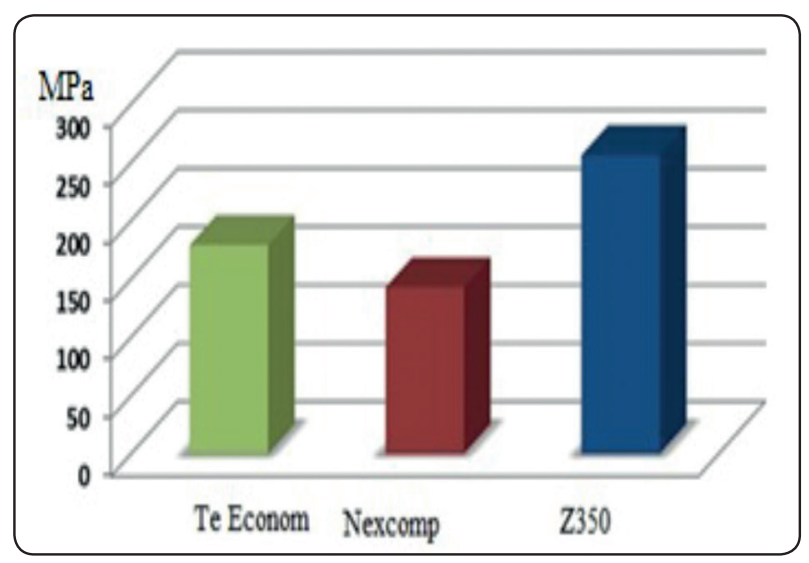

Fig. (1): Bar chart representing the compressive strength (MPa) among different tested materials

\section{Diametral tensile strength (DTS) results}

Results of diametral tensile strength results are shown in figure (2). The nanofilled resin composite showed significantly higher mean DTS value $(48.9 \mathrm{MPa})$ than nanohybrid type (36.2MPa), $(\mathrm{p}<0.05)$. no significant difference was found between the microhybrid $(42.6 \mathrm{MPa})$ type the two other types; $(\mathrm{p}=0.3)$.

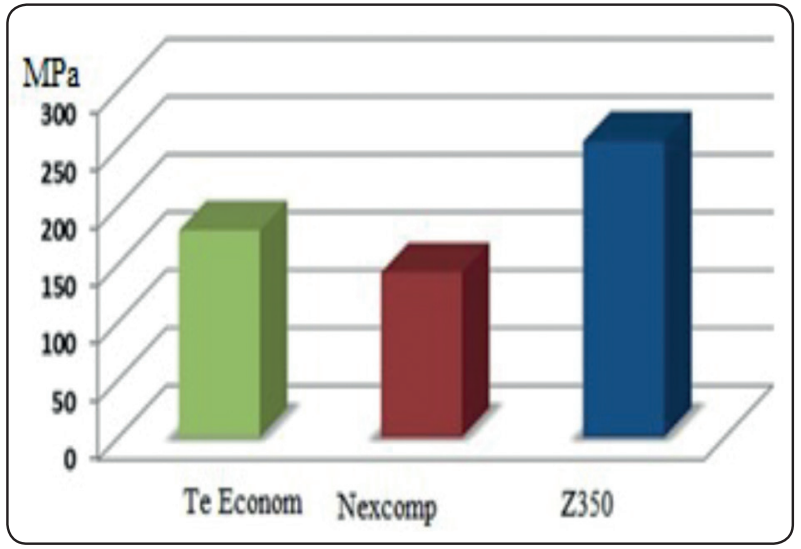

Fig. (2): Bar chart representing the DTS (MPa) among different tested materials 


\section{Surface hardness testing results:}

The microhybrid type showed the highest insignificant Vickers hardness value (68.2 VHN) when compared to the nanofilled type (65.8 VHN), $(\mathrm{p}=0.7)$. least significant hardness value (44.6 VHN) was revealed by the nanohybrid type when compared to the microybrid and the nanofilled types $(\mathrm{p}<0.05)$.

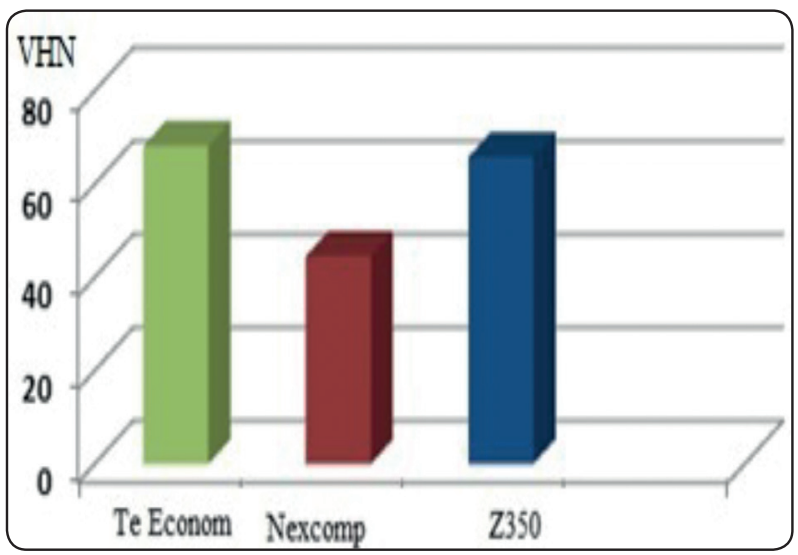

Fig. (3): Bar chart representing the hardness (VHN) among different tested materials

\section{DISCUSSION}

Nowadays, aesthetic restorations have become the first demand of most of the patients. Resin composites have the privilege performance as direct and indirect restorations; governed by maximum preservation of the tooth tissues and great esthetic properties. They also serve as a reliable core material against different subjected stresses in the oral cavity. Continuous developments in resin composites matrices and fillers in the material industry are going on to fulfill such target.

Tensile and compressive strengths testing measures the maximum strength, the filler and resin matrix could withstand and describes the cohesion of materials under tensile and compressive stresses ${ }^{\left({ }^{8}\right)}$. Chemical composition of the resin matrix as well as filler particles size, distribution, shape and surface treatment are among the main factors affecting their mechanical properties including the compressive strength of a restoration ${ }^{(10)}$. The resin matrix in the three commercial resin composites share the presence of Bis-GMA and TEGDMA monomers. However, the tested nano filled resin composite type has additional monomer type; PEGDMA added probably to decrease the matrix shrinkage, and to allow for maximum filler loading of nanosized particles (20 nm silica, 4-11nm Zr) and nanoclusters $(0.06-10 \mu \mathrm{m})^{(11)}$. Moreover, the presence of spherical shape nanoparticles in the nanofilled composite have the privilege of increasing the strength of a restoration as stresses are more prone to concentrate at the sharp angles. This may explain the highest significant value of CS of nanofilled resin composite type. However both micohybrid resin composite and nanohybrid share the same cluster fillers size range $(0.04-7 \mu \mathrm{m})$ that may suggest the insignificant difference of CS between both types.

A positive correlation was found between compressive strength and diametral tensile strength where fracture results because of complex and tensile shear stresses within the material ${ }^{(12,13)}$. The diametral tensile strength test results; also showed significantly higher values of nanofilled composite type than the nano hybrid resin composite. The high filler loading of nanoparticles with their superior mechanical properties may be the reason for the obtained result. However, the insignificant difference of microhybrid resin composite compared to both nanofilled and nanohybrid types; may be due to the intermediate filler consistency of the hybrid resin composites. Furthermore, the hybrid filler particles are more liable for dislodgment out of the resin matrix that genuinely may affect their strength ${ }^{(10)}$.

According to Davari et al; 2012, the DTS of nano-filled composite was in the range of (26$32 \mathrm{MPa}$ ), with statistical insignificant difference in the compressive strength results between the tested nanofilled and nanohybrid composite resin types ${ }^{(14)}$. Such results proposed to be related to the effect of different resin matrix used in different 
composite types. Studies reported that the addition of low molecular weight resins; e.g. TEGDMA and /or UEDMA to Bis-GMA increases the diametral tensile strength ${ }^{(15,16)}$.

Surface hardness testing of resin composite is a reliable test to evaluate the degree of conversion of resin matrix which is directly related to its wear resistance and stability in the oral environment ${ }^{(17)}$. Among factors that influence the hardness of the dental resin composites are; the resin type, shade, filler loading, curing time source of light, time of exposure and distance of radiation ${ }^{(10,12)}$. Large filler size proved to increase the light scattering efficiency from curing light, decreasing the degree of conversion hence; the hardness values (18-20). Such finding could explain the results obtained in the current study, where the tested nano hybrid type showed the lowest VHN, with insignificant difference between the tested Nanofilled and microhybrid composites types.

\section{CONCLUSIONS}

Within the limitation of the present investigation it could be concluded that; nanofilled resin composite had the highest mechanical strength results, adequate for use as a core material; while the nanohybrid resin composite was the least regarding the tested mechanical strength properties.

\section{REFERENCES}

1. Cramer. J.W. Stansbury, C.N. Bowman. Recent Advances and Developments in Composite Dental Restorative Materials. J Dent Res, 2011; 90(4):402-416.

2. Terry DA. Applications of nanotechnology. Pract Proceed Aesthet Dent, 2004;16: 220 -222.

3. Goldstein MB. Rapid-fire posterior resins. The unwritten. taking advantage of nanocomposite technology. Dent Today, 2004; 23: 60-65.

4. Terry DA. Direct applications of a nanocomposite resin system, Part 1: The evolution of contemporary composite materials. Pract Proceed Aesthet Dent, 2004; 16:417- 422.
5. Yap AUJ, Tan CH, Chung SM. Wear behaviour of new composite restoratives. Oper Dent, 2004;29:269 -274.

6. Irini D. Sideridou, Maria M. Karabela, Evangelia Ch. Vouvoudi .Physical properties of current dental nanohybrid and nanofill light-cured resin composites. Dental materials, 2011; 27: 598-607.

7. American Dental Association Certification programs of the council on Dental Materials, Instruments and Equipment. American National Standards Institution / American Dental Association Specification 27 for direct filling resins. Chicago: American National Standards Institution/ American Dental Association; 1977.

8. Bulem Yuzu gullu, DDS, Yalc, DDS, Gu“ lbin Saygı1ı, DDS, enay Canay, DDS. Diametral Tensile and Compressive Strengths of Several Types of Core Materials. Prosth. J., 2006; 10: 1111-1532.

9. Hamouda I. Effect of various beverages on hardness, roughness and solubility of esthetic restorative materials. J Esth Rest Dent, 2011; 23: 315-322.

10. Power JM. Sakaguchi RL. Craig's Restorative Dental Materials, $13^{\text {th }}$ edition USA Mosby, Elsevier, 2012; 189-212.

11. Filtek Z350 XT, 3M, ESPE technical product profile.

12. Anusavice KJ. Phillips. Science of dental materials. $11^{\text {th }} \mathrm{ed}$. St. Louis: W B Saunders; 2003; p 75- 101.

13. Palin WM, Fleming GJ, Burke JF, Marquis PM, Randall RC. The reliability in flexural strength testing of a novel dental composite. J Dent, 2003; 31(8):549-57.

14. Davari A, Kazemi A, Mousavinasab M, Yassaei S, Alavi A. Evaluation the compressive and diametric tensile strength of nano and hybrid composites. Dent Res J, 2012; 9 (6): 827-837.

15. Aguiar FH, Braceiro AT, Ambrosano GM, Lovadino JR. Hardness and diametral tensile strength of a hybrid composite resin polymerized with different modes and immersed in ethanol or distilled water media. Dent Mater, 2005; 21(12):1098-103.

16. Geirsson J, Bayne SC, Swift EJ Jr, Thompson JY. Mechanical property characterization of a novel directlyplaced ceramic restorative material. Am J Dent, 2004; 17(6):417-21.

17. Topcu F, Erdemir U, Sahinkseen G, Yildiz E, Uslan I. Evaluation of micro-hardness, surface roughness and 
wear behaviour of different types of resin composites polymerized with two different light sources. J Biomed Mater Res, 2010; 92B: 470-478.

18. Braga RR, Ferracane JL. Contraction stress related to degree of conversion and reaction kinetics. J Dent Res, 2002; 81: 114-118.
19. MacCABe JF\& WASSELL R W: Hardness of model dental composite- the effect of filler volume fraction and silanation. J Mat Sci Mat Med, 1999; (10) 291-294.

20. Conti C, Giorgini E, Landi L, Putignano A, Tosi. Spectroscopic and mechanical properties of dental resin composites cured with different light sources. J Mol Struct, 2005; (744-747):641-646. 